\title{
Littles: Affects and Aesthetics in Sexual Age-Play
}

\author{
Katrin Tiidenberg ${ }^{1}\left[\right.$. Susanna Paasonen ${ }^{2}[$
}

Published online: 11 December 2018

(C) The Author(s) 2018

\begin{abstract}
This article explores the experiences and practices of self-identifying female sexual age-players. Based on interviews and observation of the age players' blogged content, the article suggests that, rather than being fixed in one single position, our study participants move between a range of roles varying across their different scenes. In examining accounts of sexual play, we argue that the notion of play characterizes not only their specific routines of sexual "scening" but also sexual routines, experimentations, and experiences more expansively. Further, we argue that a focus on play as exploration of corporeal possibilities allows for conceptualizing sexual preferences and practices, such as age-play, as irreducible to distinct categories of sexual identity. The notion of play makes it possible to consider sexuality in terms of transformations in affective intensities and attachments, without pigeonholing various preferences, or acts, within a taxonomy of sexual identities. In doing so, it offers an alternative to the still prevalent categorical conceptualizations of sexuality that stigmatize people's lived experiences and diminish the explanatory power of scholarly and therapeutic narratives about human sexuality.
\end{abstract}

Keywords Sexual age-play $\cdot$ Littles $\cdot$ Play $\cdot$ Affect $\cdot$ Tumblr

As role-play pertaining to age, age-play is broadly considered a subset of BDSM (encompassing bondage and discipline, dominance and submission, sadism and masochism; see Weiss 2011 for a discussion of the "paradigmatic theatrality" of BDSM; see also Harviainen 2011 for a discussion of BDSM as "live action role play" or kinky role-play). Age-players may take on heteronormative or genderqueer versions of the roles of Daddy or Mommy (sometimes Headmaster/Headmistress)

Susanna Paasonen

suspaa@utu.fi

Katrin Tiidenberg

katrin.tiidenberg@gmail.com

1 Baltic Film, Media, Arts and Communication School, Tallinn University, Narva rd 27, 10120 Tallinn, Estonia

2 Media Studies, University of Turku, 20014 Turku, Finland 
dominants playing with little girl or little boy submissives ${ }^{1}$ in heterosexual and homosexual, sexual and non-sexual constellations alike (Leatherati 2013; Bauer 2018). ${ }^{2}$ Age-player Littles can be teens, toddlers, or babies (Hawkinson and Zamboni 2014; Zamboni 2017). In addition to the variety of roles and positions it affords, age-play ranges in its intensities from casual explorations to committed, immersive lifestyles.

In his popular overview of the sexual subculture of age-players, Rulof (2011, pp. 19-33) charts it as ranging from people reliving childhood to rewriting it, practicing care, exploring different gendered childhoods and options, performing innocence, relaxing through regression and enjoying the play as a sexual fetish. Across these routines and functions, the notion of play does not connote "something trivial or frivolous. Rather, many people take ageplay very seriously" as something that is part of, or informs their ways of experiencing and making sense of themselves (Rulof 2011, p. 7; see also Taylor and Ussher 2001; Stear 2009; Newmahr 2010; Richards 2015; Wignall and McCormack 2017 for analyses of kink practices as play, theatrical practice, make-believe, or leisure). Writing in the context of game studies, Sicart (2014) addresses play as entailing "the immense variations of pleasure in this world," yet without these pleasures being "always submissive to enjoyment, happiness, or positive traits" (p. 3.) Taking on this definition of play as variations of pleasure, this article sets out to examine age-play as play, namely as autotelic activity practiced for its own sake.

In doing so, we aim to intervene in the pathologized framing of age-play as paraphilic infantilism (e.g. Doshi et al. 2018), which occurs despite the Diagnostic and Statistical Manual of Mental Disorders-V stating that "most people with atypical sexual interests do not have a mental disorder," and paraphilic infantilism not being classified as a paraphilic disorder within the manual. When the widespread tendency to pathologize age-play intersects with the still prevalent normative notion of coherent and categorical sexual identity, ${ }^{3}$ people's preferences and experiences become stigmatized. It also follows that the explanatory power of popular, scholarly, and therapeutic narratives about human sexuality diminishes while definitions of, and attitudes towards age-play get locked into conceptions of a flawed self (Nichols 2014). The fixing of preferences and acts into a taxonomy of sexual identities makes it difficult to address variations in intensity, attachment, and self-definition that practices of sexual play and experimentation entail.

\footnotetext{
${ }^{1}$ Little/little dynamics are also possible, for example when there is one dominant and two or more littles. These dynamics are sometimes hierarchical and sometimes not.

${ }^{2}$ For example daddy doms/little girls (DDLG), daddy doms/little boys (DDLB), mommy doms/little boys (MDLB), mommy doms/little girls (MDLG) where roles are possibly genderqueered (i.e. Femme Daddy).

3 Sexual orientation essentialism states that sexual orientation is "biologically based, immutable, fixed early in life, and is culturally and historically universal" and/or that "sexual orientation exists in discrete and non-overlapping categories such as homosexual versus heterosexual (discreteness), and that these categories are identity defining, informative of an individual member's characteristics, and that category members are homogenous" (Morandini et al. 2015, p. 2).
} 
Margot Weiss points out that many practitioners "see BDSM as that which they do (not something that they are), a sexuality organized around practices. As an obvious example, people who do BDSM are generally called 'practitioners' or 'players,' not something like 'BDSMuals.'” (Weiss 2011, p. 11.) Weiss' separation between doing and being, between proclivity and essence, echoes Michel Foucault's critique of 19 th century scientific study of sex that mapped individuals as representatives of sexual types characterized by their inner qualities. In contrast to the earlier notion of "the sodomite" descriptive of the acts performed, the newly invented category of the homosexual "was now a species" (Foucault 1990, p. 43). In addition to giving birth to the homosexual, this shift from understanding sexuality in terms of "being," rather than "doing," gave rise to an expansive range of identity categories defined according to their deviations from assumed normalcy.

Following philosopher Bergson's (2007, p. 299) conceptual distinction, these categories of sexual identity operate through differences in kind rather than as those in degree. Understood as differences in kind, sexual preferences become seen as connected to identity categories that separate not only practices, or ways of doing, but people and their modes of being from one another. Conceptualized as differences in degree, sexuality involves fields of variation that necessitate no classification based on distinct categories. Considered in this vein, age-play does not need to involve the pigeonholing of play routines as descriptive of sexual identity. Age-play can be a preference, an interest, a like, a point of identification, and anything beyond. In addition, sexual play involves a broad and complex affective spectrum where intensities range and vary.

In what follows, we analyze the experiences and articulations of a group of female, self-identifying age players of the Little variety, and propose conceptualizing age-play outside both its pathologization as paraphilic infantilism and its fixing as an identity category. In positioning age-players as co-contributors to knowledge production on sexual play, rather than as its objects, we seek to understand the pleasures and intensities that their play routines involve. In exploring practices, perceptions, and affective dynamics of play, we further examine the broader productivity of the notion of play in theorizations of sexuality. We argue that the concept of play, when applied to sexuality, makes it possible to rethink sexuality as connected to, and as constantly transformed by the contingency of tastes and the affective registers involved in practices of pleasure. Play sets preferences, attachments, and identifications into motion, and makes it possible to highlight variation in how people make sense of their sexuality (see Paasonen 2018). We are interested in thinking through the intensities of play and their transformative power-in what drives people to ageplay and what keeps them playing.

\section{Research Context and Material}

The article builds on, and brings together, the authors' two respective research projects: a theoretical exploration on sexuality and play (on-going since 2015; see Paasonen 2018), and an extended (on-going since 2011) ethnographic study with a 
community of NSFW ${ }^{4}$ bloggers on Tumblr (cf. Tiidenberg 2014a, 2017). ${ }^{5}$ Our ensuing small-scale, interpretative, and exploratory study asks how the research participants experience and make sense of their sexuality in the context of age-play, as well as how they perceive and articulate the affective spectrum connected to the practice.

Our empirical data is generated via long-term ethnographic immersion in an online community on the platform Tumblr, which our participating age-players are part of (but which is not focused on age-play as such). This immersion has generated rich and multifaceted data allowing for thick descriptions (see Miller and Slater 2001; also Boellstorff et al. 2012, p. 38). We draw on a range of pre-existing data (interviews, fieldnotes, and blog outtakes) generated between 2011 and 2016 by Tiidenberg, and new interview data gathered in 2017 after initial re-analysis of existing material.

Our approach to sampling, data collection, and analysis has been pragmatic and iterative: we alternate between emic, or emergent, readings of the data and an etic use of existing models, explanations, and theories. In the course of this, we have revisited the data in order to see novel connections and to progressively refine our focus and understanding. (Tracy 2013, p. 184.) In more concrete terms, we used data from eight female-identifying informants gathered through a combination of snowball and purposive sampling methods (Table 1). Materials form everyone who selfidentified as age-players in Tiidenberg's initial ethnographic sample were included, and additional participants were recruited based on the recommendations from our informants. The condition of inclusion was that the people had to practice age-play and not just blog about it. This is a small, all-female, highly educated, hetero-, and bi-sexual, international, mixed-race sample involving people of different body-sizes. We acknowledge its limitations, and do not seek to generalize to any population, yet see it as offering rich interpretations of lived sexual practices, their possible functions and affective intensities.

Questions for the follow-up interviews were generated based on open-coding and analysis of the data extracted from existing material. All interviews were semistructured, allowing for emergent questions on a person-by-person basis and, like all data used here, it was subject to thematic qualitative analysis. After Tiidenberg open-coded interviews, blog outtakes, and fieldnotes from 2011-2017 (extracted for the virtue of addressing age-play and kink), both authors collaborated on analytical memo-ing. This was followed by a group interview (appropriate as all of the informants are at least "internet friends") with the same people, conducted by Tiidenberg, in order to gather more information. After another round of coding and analytical memo-ing, two additional individual interviews with two more people, as well as a second group interview were conducted to fill apparent gaps. All participants were

\footnotetext{
${ }^{4}$ NSFW—not safe for work-is an acronym widely used across the Internet to indicate mostly sexually explicit content (see Paasonen 2018).

${ }^{5}$ Tumblr is a microblogging platform founded in 2007 with circa 445 million blogs (Tumblr 2018) known until December 2018 for its fairly lax content filtering policies in terms of sexual content allowing for NSFW communities to prosper.
} 


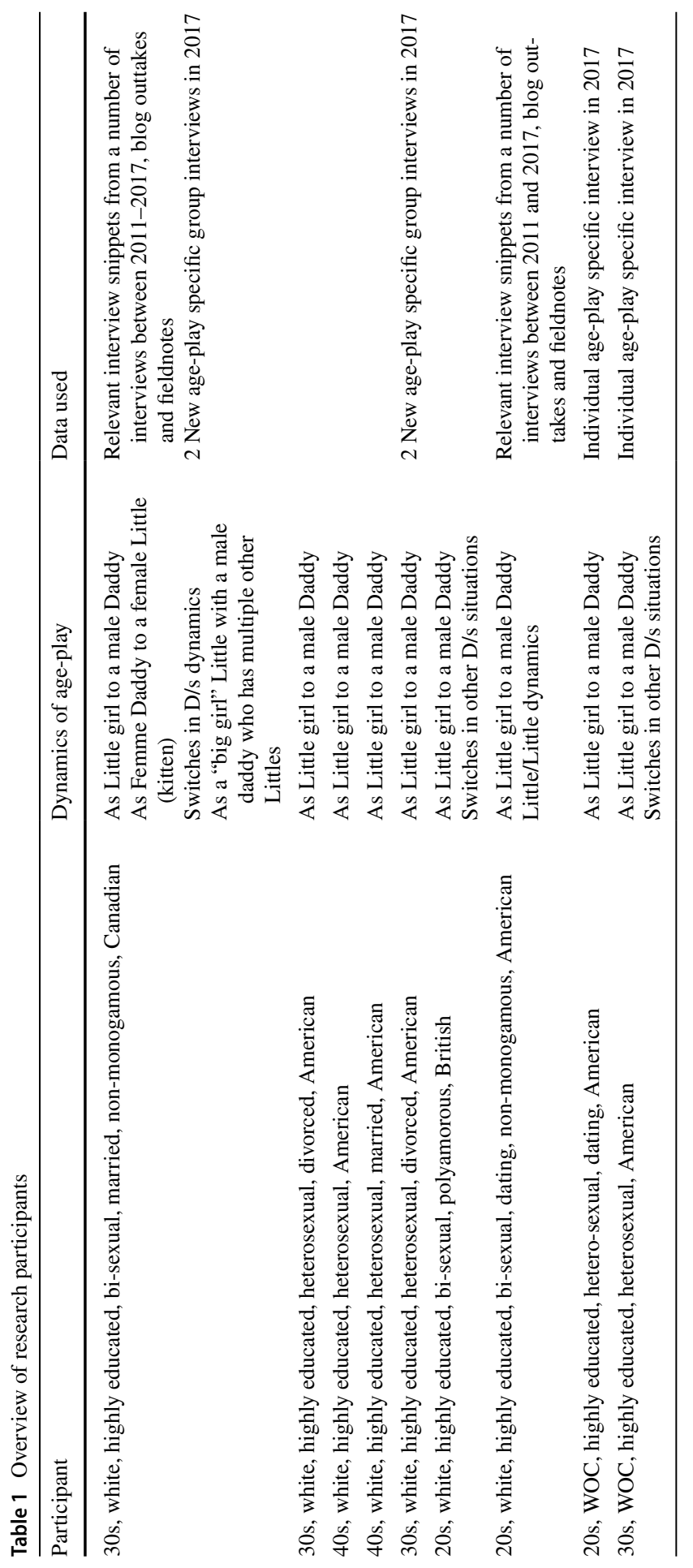


asked for and gave their informed consent for their experiences to be included in this analysis.

For our participants, sexualities are played out in both mediated and unmediated settings integrating media platforms such as Tumblr, chat apps, and online fetish communities. This is hardly a surprise, given that online platforms have long been identified as stigma interruption spaces where the "ordinary norms of everyday life easily may be suspended" (Waskul 2002, p. 205). This liminality has been shown to have high potential for self-reflexivity and self-care, as well as making it possible to reject the regime of shame connected to minoritarian sexualities (Wood 2008; Sundrud 2011; Tiidenberg 2014b). While this article does not focus on the online presentation of age-play, it is important to note that all of our informants found their own and other age players' Tumblr blogs to be an important resource for making sense of their sexuality, a safe space of exploration and discussion, as well as a tool of self-reflection.

\section{Being Little}

Looking at how our participants articulate their experiences of age-play, it becomes apparent that, rather than being fixed in one single position or identity, they move between a range of roles in various scenes of play involving different partners, some of which are serious and others rather casual. The notion of play then characterizes not only the situations and interactions involved in these sexual scenes, or in the shifts between themes, but equally in people's accounts of their own sexuality. One study participant, a woman in her 30s, plays as a Little girl to a long-term Daddy, who is male; as a Femme Daddy (not Mommy) to her female Little, whom she calls Kitten; as a one-off sub to men and a one-off Domme to women at sex parties; as a Domme to a man who is a well known Dom and has a group of schoolgirl Littles, but as his Little sub (although one that is above the others in the play hierarchy), when they play with those other subs; and finally, as an ethical non-monogamist poly wife with her husband and their various partners (the latter being more about sex and less about kink):

How would you describe your play dynamic with Mr. X and his Littles?

I play Daddy's "special friend” when we do group stuff. A big girl who gets all the privileges of being a big girl.

But you sometimes top him too, right?

I don't top him in front of the girls. We tried once but he wasn't comfortable. I top him alone every time now. And it's super intense. I play the "disappointed in you" card.

What is the dynamic when you top him - the language, the aesthetic, the kind of style or feel of it? 
It's not age-play outright. More humiliation of being put in his place. Like I made him strip naked while I was still wearing my sundress. And then decided he didn't look humble enough so I made him go to his school-girl drawer and put on a pair of the girls knee socks. For the humiliation factor. And the putting him in his place factor. But not because of the actual Little aesthetic.

What about your Daddy, do you ever switch with him?

At the start of our relationship, we switched. I learned topping by topping him! It was super cute. But after I figured out my top space, we realized we both felt better with him as top. That phase lasted about 6 months. And the remaining years I've only bottomed with him. Like we never went back.

We argue that such a diversity of positions, relations, and practices of pleasure complicates conceptualizations of age-play through or within the categories of sexual identity. The woman above does not identify as Little, or Femme Daddy, or Domme. Rather, she identifies with all these relational positions in a situated manner-some of these remain linked to specific people and others not; some are more ad hoc and others more stable. Play, then, emerges as both descriptive of sexual routines and as an analytical concept making it possible to map out the contingency of sexual likes that are experimented with in quest for pleasure.

\section{The Aesthetics of Being Little}

For our participants, aesthetics is an important element of age-play: they emphasize the need to find a style of engagement, interaction, and bodily stylization that fit the situation and allow the players to engineer its affective intensities. Some of the interviewed Littles expressed finding the aesthetic and dynamic of what they perceive as "conventional BDSM" unappealing, while still enjoying intense pain and humiliation. Others play as both Littles and as BDSM submissives depending on partner, mood and situation. In her blog, one of our participants links aesthetics with the fluidity and relationality of her sexual self:

I didn't actively explore BDSM for years, because the way it was portrayed didn't appeal to me. The typical black leather, serious mean Dom and a lowly slave didn't speak to my tastes and desires at all. I couldn't see myself in it. And then Tumblr exposed me to a lot more content that was made by women or curated by women. There was a lot of queer content, a ton of feminist content and people's personal stories that showed how they live kink in real contexts not glitzy photoshoots or porn. And this is when I realized that there are bratty submissives and little submissives, play pets and do-it-yourselfers, lady doms and femme daddies and gender queer tops and bottoms. I realized that people's kink is versatile and fluid and still authentic. So I was able to find an aesthetis and a dynamic that suited me, appealed to my senses and felt right. You build a dynamic with your partners, and it can be whatever you want it to be. So now my kink is like me, it fits me and my partners, and we create it as we 
go, building on parts that feel right until we have something that we love and can't get enough of.

By BDSM standards, the Littles we studied may play hard: a preference for juvenile aesthetics does not imply less intense play. Some of them merely perceive the aesthetics of leather BDSM as "wrong" to the extent that for them, it precludes pleasure, while others find both pleasurable, but experience a different intensity in submission within the DD/lg aesthetic and dynamic.

\section{Multiple Littles}

Our participants describe the many different ways in which they practice or see others practicing feminine ${ }^{6}$ little. "Princess Little" is described as being aroused by a particular aesthetic and performance, as well as by sensations of corruptibility. This type of little-play affords some "bitchiness, "or "topping from the bottom," in a persistently cute way. "Pet Littles" ways of play are fuelled by a desired sense of fragility, vulnerability, and the ability to trust someone to treat you very gently while also dominating you. "Daddy's girl" Littles draw on the cultural icon of Lolita (see Laing 2018) and rely on certain brattiness and boundary testing as central to the scene. This is obviously not an encompassing list but rather an illustration of the richness, detail, and nuance involved in how the women interviewed articulate their sexuality, and the affective and aesthetic nuances involved. What is important, however, is that these women do not necessarily commit to one style of being Little. Rather, their positions shift depending on the mood, the partner, as well as a myriad of personal aspects connected to headspace-an affective and cognitive shift in ways of being in and connecting with the world in BDSM play (Wignall and McCormack 2017; Busbee 2008; Cutler 2003). Furthermore, stability within these positions comes across less as an issue of identity than as a dynamic of bonding and play with a particular partner. In the interview snippet below, one of our participants explains:

Do you always play as DD/lg with him or do you ever submit to him in a different dynamic?

He is always my Daddy. I am always baby, little, dolly, pet. Some Little variation. Topping for me is an easier space. It's not vulnerable. I'm in control. Being submissive is challenging, but also hits more buttons. And being Little even more so. I just can't get myself to give over control very easily so it's not a space I go to with many people. He's been a safe place for my submission and because that's so rare, it's intoxicating. Topping often feels more service-y for me. I like it because I'm giving people what they want. I would be happy to switch with Daddy, if it was what he wanted. But Little submission is the money spot for me personally.

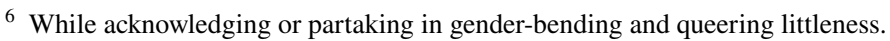


In the case of long-term partners, a dynamic that is experienced as intensely satisfying may be built in what is essentially a DIY process of play. In this process, roles may gel to the degree that people deploy alter egos (e.g. "Sweetheart," "Bunny," "Pet") and speak of themselves in the second of third person when discussing their DD/lg practices. However, as illustrated in the interview excerpt above, partners may inhabit multiple Little and Daddy roles even within a reasonably stable relational dynamic. We suggest that these roles emerge from, and belong to the play dynamic between the partners in question, and do not necessarily extend beyond them as a more firm sense of what one is, or does (although this may also be the case). For example, one of our interviewees' partnership had recently dissolved. While also playing as Little with other people, the woman stated that she felt like there was no longer an outlet for Bunny, a Little which she only played with one partner, and which she missed terribly. This suggests that the practitioners' sexual preferences, routines, and practices-and not merely their relations with partners-come into being in a process of play.

\section{Figures of Childhood}

Approaching sexuality through the notion of play allows for crossing and bringing together of several notions often considered mutually exclusive, or at least positioned as being in persistent friction with one another. For if sex is understood as the stuff of adult experience, and not that of minors, then adults are excluded from the realm of play. Sexuality has often been considered as indicative of the end of both childhood and play (Bauer 2018, p. 145). Scholars have distinguished between childhood sexual play and adult activities by contrasting the former's "curiosity and playfulness" with the latter as "marked by an understanding of sexual behaviour and its consequences" (Essa and Murray 1999, p. 232). Following this line of thinking, play is innate to children and indicative of overall openness towards the world, yet something that ends and congeals as people age. In contrast, if one understands sexuality through the conceptual prism of play as acts of exploration motivated by pleasure within which different preferences and tastes are forged, no such categorical distinction need to be made.

At the same time, age-play dynamics draw some of their appeal and some of their affective intensity from the conceptual separation of childhood, as a realm of sexual inexperience, from adult sexuality. Here, at least three figures of the child emerge. First, there is the autobiographical, recollected child that once was one's self, and that can be reconnected with through acts of role-play while also possibly affectively re-attuning these memories:

I look at pictures of myself when I was a kid and I look so seeeeeerious all the time. I just want to put that girl in pigtails and give her some bubbles and send her outside to frolic. But I wouldn't have frolicked; I would have taken care of my siblings, and fretted about my cold hands and given passing strangers anxious looks... (interview, 2017.) 
BDSM play derives some of its intensity from the incorporation of personal life experiences, attitudes, and social power dynamics into sexual scenes in ways that also afford therapeutic possibilities of processing, self-discovery, and resolution (Weiss 2006, 2011). As a form of trauma play, BDSM has been examined as a means to increase, or restore, the liveability of bodies that have undergone harm (see Barker 2005; Barker et al. 2007; Weiss 2011; Lindemann 2011; Hammers 2014). Our age-playing participants also talked about the earlier life events feeding into their routines and scenes, and it functioning as self-care:

Personally, having a stable, loving, healthy relationship with my Daddy Dom is helping me to repair some pretty heavy childhood traumas. And interestingly, my Daddy, who doesn't have a positive relationship with his actual father, finds it therapeutic to know that these nurturing and loving qualities are inside of him, regardless of the fact that he didn't learn them by example. It has been powerfully healing for him too. (interview, 2017)

The early life dynamics can make age play a means of revisiting and refiguring childhood, the actual experiences of which were marked by parental distance or irresponsibility in ways that cut childhood play short.

The second figure involves the child as a fantasy role played without it being directly connected to one's embodied memories-when, for example, playing a child of a different gender identification, a badly behaving brat that one never dared to be, or a very young infant-in ways allowing for explorations of other ways of being in the world, and possibly reimaging one's self in the process (Bauer 2018, p. 141).

The third is a symbolic, cultural figure of the child (see Edelman 2004). Distinct from empirical children, this figure operates with the ideological notion of innocence that confuses relative sexual ignorance with asexual purity, and which is in fact one of emptiness, passiveness and blankness: "a coordinate set of have nots, of negations" (Kincaid 1998, p. 15, emphasis in the original; also Higonnet 1998). Surfacing with Romanticism, this figure was, as Kincaid (1998) notes, "strangely hollow right from the start: uncorrupted, unsophisticated, unenlightened" (p. 53). At the same time, it has been eroticized as a highly valuable, as well as malleable, object of desire precisely due to these properties — or the lack thereof:

There is something a little sick about the fact that I gravitate to pastels and bridal lingerie for kink parties. About the fact that I like feigning innocence in the midst of doing something depraved. I like being the one cute little outfit in the abundance of leather and fishnets. I enjoy feeling impressionable and corruptible. There is something inherently more perverse about an outfit like that than a mesh bodysuit, and I really like it. (Blog outtake)

Here, playing child in ways that feed in and out of sexual titillation and arousal aggressively rubs against this figure of innocence. Scenes derive some of their affective intensity from this sense of incompatibility and transgression. 


\section{Badwrong}

In multiple Tumblr communities as well as within fan-fiction, ${ }^{7}$ hashtags and labels such as "badwrong," "dead dove do not eat," and "I am trash" are used to mark out fantasies that are appreciated specifically for violating taboos of sexual normalcy. The productive tension and the affective intensity involved in "badwrong" contributes to, and even organizes one's sexual fantasy, and fuels scenes of play where the perceived "badness," "wrongness," "sickness," and "perversity" of tastes can be safely enjoyed and experimented with. This is poignantly illustrated by the affective power that some of our informants experience when calling a partner "Daddy" (even compared to calling them "Sir"):

And I was lying there in this intensifying space of both feeling so much love for him, and arousal, and then also vulnerability, fear and a certain kind of wrongness-like being taken advantage of, or used. And I just started feeling like I was gonna say it, like it was just gonna come out of me-Daddy! (interview 2017, on the first time a self-identified little called their partner "daddy").

Calling a partner "daddy," and negotiating age play has been more and less difficult for our participants depending on their personal perception of taboo, their native language and culture (calling a male partner daddy has arguably been somewhat normalized by some musical (sub)cultures in English or Spanish, while quite uncommon in other languages), the situation and the partner. Both the anxiety of breaching the use of age-play-specific titles in sexual role-play and the affective intensity from being able to use such language is fed by the discussed friction between the figures of child and the perceptions of adult sexuality. The different figures of child acted out, and the diverse positions of dominance and submission deployed, afford fluid, adjustable experiences and manageable intensities of "badwrong."

\section{Rejection of Pedophilia}

Although acted out among willing adults, the playful crossing of the boundaries of childhood and adulthood, with the ideological and moral concerns that they entail, remains rife with tension. As a field of practice, age-play taps into a range of concerns regarding the motivations of playing baby, toddler, or pre-teen, to act as nurse, parent, or carer for one. The heavy shadow of pedophilia in fact never seems to loom too far away. This theme is recurrently probed in our participants communities and blogs on Tumblr as well. People who maintain age-play related blogs or address their preference for this type of play routinely receive comments trying to position their preference as deviant-even within this specific context of NSFW social

\footnotetext{
7 Writings by fans of any media text that start from the premises and characters of the original text but expand into alternate scenarios, universes, and relationships.
} 
media. Typically, such critiques link DD/lg to pedophilia, ${ }^{8}$ and they are quickly refused and critiqued in return:

I am a little, but I am perfectly happy with my age. I don't want to be younger. I am, however, turned on by innocence, the contrast between innocence and maturity, the power dynamics, submission, roleplay, bondage, S/m, abuse, rape play and much more. I'm a strong and very smart woman. DD/lg allows me to feel weak, or small, or feminine, or silly and emotionally young, when I want to. My kink allows me to find and enjoy the young, innocent, feminine and weak within myself through my play. (Blog outtake.)

Accusations of pedophilia are responded to with great detail and reflexivity, even with references to scholarship on the topic. Such posts are often reused, should similar critiques resurface with new blog readers. In the process, responses grow in size and become FAQ posts that other Littles embroiled in online battles can use as to defend their right to play this way.

\section{Doing and Being}

The Littles in our study articulate the multiplicity of positions, spaces, roles, and dynamics that they occupy through the varying affective intensities involved in each. In this group interview excerpt, a distinction is made between age-play as role-play and more substantial, forms of being Little connected to immersion and fullness of experience:

Person 1: Like if you bring role-play/age play in, different ages have different levels of agency and different understandings of the world around them, right? But I'm me when I'm Little, I'm only a different age if we're doing some age play stuff.

Person 2: That's the big difference. I'm me when I'm feeling "sacred Little," when I'm age playing, I'm putting it on. And the thing is, the scenes can be the same. I could be eating a PB\&J and age play, or eating a PB\&J and being "sacred Little."

Person 3: For me Littleness is a deeper level of giving up control. Like there's being submissive, and then being Little is a level down from there. Being subby but not Little is much easier.

Person 2: And Little is not always pretty/fun. Whereas age-play is for fun.

Person 1: I agree.

\footnotetext{
${ }^{8}$ Claims about DD/lg being a subjugating play-position for female submissives are common too (for discussions regarding broader female submission within BDSM and its compatibility with feminism cf. Hopkins 1994; Stear 2009). These claims are also routinely rebuked by bloggers who partake in age play. 9 "Sacred Little" is discussed in more detailed further on, but implies a truly intense experience of "subspace" or "Little space.".
} 
Person 2: Little is crying for real, accessing real emotion.

Person 1: And needing to be taken care of.

(Group interview, 2017)

As we have argued above, if deployed as normative and categorical constructs, sexual identities pigeonhole tastes and desires into taxonomies in ways that do not necessarily do justice to how people make sense of their selves. For our informants, age-play entails variations in intensity from doing Little (as titillation, or as part of a sexual routine) to being Little when sexual play grows central to their self-definition. This sense of being Little need not be conflated with Foucault's (1990) discussion of understanding sexuality categorically as a matter of being rather than one as doing: rather, it refers to the strength and quality of attachments that people have to their play roles, scenes, and partners, as well as the centrality that they see these as occupying in their overall ways of being in the world. Bergson's (2007) notion of differences in degree (rather than those in kind) helps to accommodate this range of intensities and attachments when discussing sexual preferences. It then follows that we conceptualize ways doing and being Little as an issue of variations in intensity - and as ranging from experimentation and interest to routine and self-definition-without beginning from, or finishing with, their classification as a sexual identity.

\section{Affective Intensities}

The notion of affect, as it has been subtly weaving in and out of this article, makes it possible to conceptualize both the intensities of play and the transformations that occur in people's sexual preferences and routines. Play involves qualities and registers of affect connected to pleasure. Affect is aroused in ways and through factors that individuals can scarcely control, yet without it "nothing else matters-and with its amplification, anything else can matter. ... It lends power to memory, to perception, to thought, and to action no less than to the drives" (Tomkins 2008, p. 620). For Tomkins (2008, p. 188), the affective amplifier of excitement, in particular, is perquisite for sexual desire to push through mundane events and obligations (also Frey 1991).

If excitement is lacking, it may be hard to be in the right mood so that the activity becomes drained of enchantment and gratification. In the context of BDSM, this mood is regularly addressed as headspace that is situational and differs from person to person. Headspace can range from a narrowing down of affective focus onto one's subject position as a dominant or a submissive to a state of completely altered consciousness equaling being high on strong drugs. Subspace, or "drop," is a particularly intense state entailing a dramatic increase in adrenaline and endorphins that accompany submission, and possibly pain. (Busbee 2008.) Our participants describe their experiences with DD/lg headspace as gradations of experience, within which truly intense experiences of littlespace were described as "sacred," as in "sacred space" and "sacred Little:" 
I think littleness is a really sacred and important space for me (...) that feeling of letting go of control and letting someone else drive, and not having to stay in control ... no layers or masks or boundaries or walls or whatever, just stripped down vulnerability and being. I have aspects of littleness in my everyday personality too, for sure ... dishes with piglet on them, having pink hair, pigtails, My Little Pony leggings etc. But in my D/l dynamic it was really the first time I've been allowed to just be that side of me. A relationship where someone took the role of caregiver or person in charge, during particular moments, so I could have space to pull back those layers and be that playful wide-eyed self. So it's not a role I step into, it's more like a space of myself I'm allowed to access. (Interview with a self-identified little on the topic of DD/lg play, 2017)

Experiences of sexual play range in their affective registers and intensities. Negative intensities can bar access to pleasure by rendering the scene awkward, strained, or pained. A play scene can flip from arousing to non-arousing within a blink of an eye without the inherent features of characteristics of an act or a situation changing. If the mood is ruptured, it may just evaporate; and if one falls out of headspace, it may be difficult to recapture. Meanwhile, other negative affective intensities like shame, fear, disgust, or guilt can-perhaps counter-intuitivelyintensify and amplify sexual desire and arousal. They add an edge of transgression to the encounters at hand, be it from enjoyments taken in humiliation or variations of edge-play.

\section{Shame and Humiliation}

Sexual play can cater strained and dark intensities that push bodies away from their zones of comfort towards novel sensations, encounters, and routines. For our participants, this complexity and heterogeneity of affective intensities, addressed above as "badwrong," is particularly intense in the case of $\mathrm{DD} / \mathrm{lg}$, where, due to its normative associations, an element of shame is ever present.

I think I was imprinted when I was young to link shame with my sexuality. Shame and a power dynamic. And the Little thing feels like a safer way to experience that. To not just revisit, but to almost rewrite it. I used to feel like there's nothing you get from the Little dynamic that you don't get from regular $D / s$, it's just the tools and aesthetics are different, but now I think I was trying to bunch it all together so I'd be more palatable for the non-caregiver folk. (Group interview with women who self-identify as Littles on the topic of DD/ $\lg$ play, 2017)

The shame or embarrassment of the $\mathrm{DD} / \mathrm{lg}$ "badwrong" is perceived as being different from the humiliation associated with "conventional" BDSM:

I don't go for slave style humiliation that I would associate with that tag in BDSM, like it feels too mean, *laughs*. But I definitely like that blushy embar- 
rassed type of shame. Like, when someone realizes you're really wet from some depraved shit. (Group interview with women who self-identify as Littles on the topic of DD/lg play, 2017)

In Tomkins' affect theory, humiliation is an intensified form of shame that can be paralyzing in its reverberations (see Tomkins 2008, p. xix, 185). Embarrassment, again, represents a more fleeting, and much less encompassing experience of shame. As Allen (2015, p. 65) points out, Tomkins' affect theory allows for considering sexuality "as a set of affective curves that are always characterized by the affects of excitement and/or enjoyment" without which the experience lacks intensity. These curves may well operate in the registers of pain and humiliation, as well as in connection with myriad objects, scenes, and sites, given that there "is literally no kind of object which has not historically been linked to one or another of the affects. Positive affect has been invested in pain and every kind of human misery, and negative affect has been experienced as a consequence of pleasure and every kind of triumph of the human spirit." (Tomkins 2008, p. 74.) The affective curve of enjoyment may give way to excitement without such shifts being consciously registered, but, once noticed, it may be sought after or attempted to engineer. Furthermore, there are endless variations in degrees of experience with any affect, which can be "enjoyed in innumerable ways" (Tomkins 2008, p. 78). An embrace may spark desires and inclinations of a sexual kind, or remain comfortable as such, while a smarting lash of a whip can shock and hurt as well as fuel intense sexual excitement. An experience of embarrassment may be highly enjoyable, but should the scene move towards humiliation within the affective intensities of shame, one may soon be turned off.

\section{Comfort and Care}

Many Littles emphasize the bodily sense of comfort, safety, and pleasure derived from play - from extended physical proximities to a profound sense of securitybe this in connection with subspace, experiences of "badwrong," or something else. Pleasure taken in comfort and care can remain an end in itself, or be part of sexual scenes. Again, the issue is one of gradations of experience: of differences in degree rather than ones in kind (Bergson 2007). As described by our Littles, during play, their caregivers are able to coax out intense vulnerability on the basis of trust. This allows Littles to give up control, but they feel they need intense care work and emotional labor from their partners in return. While aftercare is an important aspect across BDSM cultures (Cutler 2003; Mondin 2017), our informants experience the $\mathrm{DD} / \mathrm{lg}$ dynamic as coming with a higher perceived need for, and intensity of aftercare, which they pair with the higher affective intensity involved in this kind of play. The following blog outtake offers one description of the embodied, sensory, affective state that is sought out in play:

Today I just want to surrender. I want someone else to worry about the details, take care of this mouth and this body. I want someone else to make all of the choices and do all of the thinking. I want to succumb to caring hands, soothing sounds, full attention, good intentions. Let me be something precious. 
This group of practitioners often uses the term "precious" to describe the affective state sought in DD/lg play that differentiates it from other types of play-and from what they call "conventional" BDSM in particular. In this context, precious is a playful, relational term implying a type of care-work that defines the play scene as something of an expected constant across its affective curves.

\section{Conclusion}

Age play (i.e. consenting adults roleplaying in some way pertaining to age), is a fairly under-researched and often misunderstood sexual subculture that is commonly ridiculed and pathologized in popular media (Paasonen 2018, pp. 86-93). In this article, we have analyzed the experiences and articulations of a small group of female, self-identifying age-players of the Little variety. Our sample is limited, but our data is thick and nuanced, allowing us to offer a rich glimpse at one way of doing DD/lg sexual role-play. This leads us to propose conceptualizing age-play outside both its pathologization as paraphilic infantilism, and its fixity as an identity category. In addition, we suggest that play-defined as autotelic activity that entails variations of pleasure not necessarily submissive to enjoyment (Sicart 2014, p. 3) is a productive lens for making sense of both age-play and sexuality in a broader sense. Conceptualizing sexuality in the framework of play unfixes sexual practices from categorical notions of sexual identity that can be used to stigmatize people's sexual preferences and experiences.

Our study participants addressed the multiplicity of their play positions (submissive and dominant, age-related and not), including the different Little-positions that they inhabit. We found their play practices to emerge as relational and situational. Finally, their experiences and articulations illuminate how important aesthetics, and the frictions between adult, sexual practices and the cultural figures of child are for getting into and maintaining a mood often called "headspace" or "badwrong." This headspace gives rise to the affective curves of age-play, and is seen to make possible the affective intensities that are both expected and sought out in it. In order to respect the richness and nuance of our empirical research material, and to arrive at a conceptual framework suitably flexible for explaining it, we have supplemented the notion of play with elements of Tomkin's (2008) theorization of affect and with Bergson's (2007) concept of differences in degree (as opposed to those in kind).

Using the notion of play as a sense-making lens to conceptualize age-play foregrounds the centrality and complexity of pleasure as its fuel and motivation, while also helping to detach inquiries into the sexual subculture from identities as loci of classification, knowledge, and power. By focusing less on what age-players are than on what they $d o$, and on how they make sense of their own practices and experiences, we have explored the affective dynamics of sexual play and the ways in which it taps into the contingency of sexualities. Moving in and out of "little-space" as the affective, sensory, and cognitive attunement for sexual play, our participants experiment with different ways of relating, sensing, doing, and being.

Driven by the quest for bodily pleasure, sexual play more or less gradually transforms and expands the horizons of what people may imagine doing or preferring 
(Bollen and McInnes 2006). Through play, it is possible to explore sensations that have been previously unknown, unimagined, even unwanted. This exploration, in turn, affords an expansion in being, imagining, and acting. Playful experimentation can therefore be seen as fundamental to how one's sexual preferences and identifications shift and transform, both in connection with and as detached from the practices of any singular sexual subculture or scene. This constant reorganization of desire then challenges the notion of a sexual self as something constant and clear in its orientations, tastes, and interests (Berlant 2012, p. 65).

Encompassing diverse dynamics and rhythms, age-play involves the exploration of bodily capacities and desires that make it possible to move between different roles and thrills. As we have argued, interrogating age-play as play-as practices of pleasure and experimentation-opens up ways of thinking through the affective curves of comfort, sexual arousal, trust, vulnerability, and transgression without fixing either the players or their preferred routines in distinct, let alone often stigmatized categories of sexual identity. With this, we hope to contribute to ongoing theoretical and practical discussions on human sexuality, both in terms of fleshing out the extant knowledge on age play, and by offering an alternative conceptualization of sex as a practice of pleasure grounded in intensities of experience. The notion of play is central to understanding what drives particular sexual scenes, how players move between roles, positions, and headspaces, and how they come to discover sexual thrills, pleasures, and intensities in the process.

Funding Open access funding provided by University of Turku (UTU) including Turku University Central Hospital.

OpenAccess This article is distributed under the terms of the Creative Commons Attribution 4.0 International License (http://creativecommons.org/licenses/by/4.0/), which permits unrestricted use, distribution, and reproduction in any medium, provided you give appropriate credit to the original author(s) and the source, provide a link to the Creative Commons license, and indicate if changes were made.

\section{References}

Allen, S. (2015). Feeling fetishes: Toward an affective theory of sexuality. Unpublished Ph.D. thesis, women, gender, and sexuality studies, Emory University.

Barker, M. (2005). On tops, bottoms and ethical sluts: The place of BDSM and polyamory in lesbian and gay psychology. Lesbian and Gay Psychology Review, 6(2), 124-129.

Barker, M., Gupta, C., \& Iantaffi, A. (2007). The power of play: The potentials and pitfalls in healing narratives of BDSM. In D. Langdridge \& M. Barker (Eds.), Safe, sane and consensual: Contemporary perspectives on sadomasochism (pp. 197-216). Basingstoke: Palgrave Macmillan.

Bauer, R. (2018). Bois and grrrls meet their daddies and mommies on gender playgrounds: Gendered age play in the les-bi-trans-queer BDSM communities. Sexualities, 21(1-2), 139-155.

Bergson, H. (2007). Matter and memory (N. M. Paul \& W. S. Palmer, Trans). New York, NY: Cosimo.

Berlant, L. (2012). Desire/love. New York, NY: Punctum Books.

Boellstorff, T., Nardi, B., Pearce, C., \& Taylor, T. L. (2012). Ethnography and virtual worlds: A handbook of method (Kindle ed.). Princeton: Princeton University Press.

Bollen, J., \& McInnes, D. (2006). What do you like to do? Gay sex and the politics of interaffectivity. Gay \& Lesbian Issues and Psychology Review, 2(3), 107-113.

Busbee, E. R. (2008). Power exchange: Interaction and identity in the BDSM community. Ph.D. thesis. New Haven: Yale University. 
Cutler, B. (2003). Partner selection, power dynamics, and sexual bargaining in self-defined BDSM couples. Dissertation, Submitted to the Institute for the Advanced Study of Human Sexuality, San Francisco, California.

Doshi, S. M., Zanzrukiya, K., \& Kumar, L. (2018). Paraphilic infantilism, diaperism and pedophilia: A review. Journal of Forensic and Legal Medicine, 56, 12-15.

Edelman, L. (2004). No future: Queer theory and the death drive. Durham, NC: Duke University Press.

Essa, E. L., \& Murray, C. I. (1999). Sexual play: When should you be concerned? Childhood Education, 75(4), 231-234.

Foucault, M. (1990). The history of sexuality, vol. I: An introduction (R. Hurley, Trans.). London: Penguin.

Frey, K. S. (1991). Sexual behaviour as adult play. In J. E. Kerr \& M. J. Apter (Eds.), Adult play: A reversal theory approach (pp. 55-69). Amsterdam: Swets \& Zeitlinger.

Hammers, C. (2014). Corporeality, sadomasochism and sexual trauma. Body \& Society, 20(2), 68-90.

Harviainen, J. T. (2011). Sadomasochist role-playing as live-action role-playing: A trait-descriptive analysis. International Journal of Role-Playing, 2, 59-70.

Hawkinson, K., \& Zamboni, B. D. (2014). Adult baby/diaper lovers: An exploratory study of an online community sample. Archives in Sexual Behavior, 43(5), 863-877.

Higonnet, A. (1998). Pictures of innocence: The history and crisis of ideal childhood. London: Thames \& Hudson.

Hopkins, P. D. (1994). Rethinking sadomasochism: Feminism, interpretation and simulation. Hypatia, 9(1), 116.

Kincaid, J. R. (1998). Erotic innocence: The culture of child molesting. Durham, NC: Duke University Press.

Laing, M. (2018). Rewriting Lolita in fashion photography: Candy, consumption, and dying flowers. Sexualities. https://doi.org/10.1177/1363460717736719.

Leatherati. (2013, May 9). A little this, a little that: What is age play? (blog post). https://leatherati.com/a-littl e-this-a-little-that-what-is-age-play-a74f93633292.

Lindemann, D. (2011). BDSM as therapy? Sexualities, 14(2), 151-172.

Miller, D., \& Slater, D. (2001). The Internet: An ethnographic approach. Paris: Berg Publishers.

Mondin, A. (2017). "Tumblr mostly, great empowering images:” Blogging, reblogging and scrolling feminist, queer and BDSM desires. Journal of Gender Studies, 26(3), 282-292.

Morandini, J. S., Blaszczynski, A., Ross, M. W., Costa, D. S. J., \& Dar-Nimrod, I. (2015). Essentialist beliefs, sexual identity uncertainty, internalized homonegativity and psychological wellbeing in gay men. Journal of Counseling Psychology., 62(3), 413-424.

Newmahr, S. (2010). Rethinking kink: Sadomasochism as serious leisure. Qualitative Sociology, 33, $313-331$.

Nichols, M. (2014). Couples and kinky sexuality: The need for a new therapeutic approach. In Y. Nelson \& H. Winawer (Eds.), Critical topics in family therapy (pp. 139-149). New York: Springer.

Paasonen, S. (2018). Many splendored things: Thinking sex and play. London: Goldsmiths Press.

Richards, C. (2015). Further sexualities. In C. Richards \& M. J. Barker (Eds.), The Palgrave handbook of the psychology of sexuality and gender (pp. 60-76). Basingstoke: Palgrave Macmillan.

Rulof, P. (2011). Ageplay: From diapers to diplomas. Las Vegas, NA: The Naxca Plains Corporation.

Sicart, Miquel. (2014). Play matters. Cambridge, MA: MIT Press.

Stear, N. (2009). Sadomasochism as make-believe. Hypatia, 24, 21-38.

Sundrud, J. (2011). Performing asexuality through narratives of sexual identity. A Masters of Arts thesis presented to the Department of Communication Studies San José State University. Retrieved November 28, 2018 from http://scholarworks.sjsu.edu/cgi/viewcontent.cgi?article=5119\&context=etd_theses.

Taylor, G., \& Ussher, J. (2001). Making sense of S\&M: A discourse analytic account. Sexualities, 4, 293-314.

Tiidenberg, K. (2014a). There's no limit to your love - scripting the polyamorous self. Journal für Psychologie, 22(1), 1-27.

Tiidenberg, K. (2014b). Bringing sexy back: Reclaiming the body aesthetic via self-shooting. Cyberpsychology: Journal of Psychosocial Research on Cyberspace. https://doi.org/10.5817/CP2014-1-3.

Tiidenberg, K. (2017). "Nude selfies til I die" - making of sexy in selfies. In P. G. Nixon \& I. Düsterhöft (Eds.), Sex in the digital age. Routledge.

Tomkins, S. (2008). Affect imaginary consciousness: The complete edition. New York: Springer.

Tracy, S. (2013). Qualitative research methods: Collecting evidence, crafting analysis, communicating impact. Oxford: Blackwell Publishing.

Tumblr. (2018, November 28). https://www.tumblr.com/about.

Waskul, D. (2002). The naked self: Being a body in televideo cybersex. Symbolic Interaction, 25, 199-227. 
Weiss, M. D. (2006). Working at play: BDSM sexuality in the San Francisco Bay Area. Anthropologica, 48(2), 229-245.

Weiss, M. (2011). Techniques of pleasure: BDSM and the circuits of sexuality. Durham, NC: Duke University Press.

Wignall, L., \& McCormack, M. (2017). An exploratory study of a new kink activity: "Pup play". Archives of Sexual Behavior, 46(3), 801-811.

Wood, E. A. (2008). Consciousness-raising 2.0: Sex blogging and the creation of a feminist sex commons. Feminism \& Psychology, 18, 480-487.

Zamboni, B. D. (2017). A qualitative exploration of adult baby/diaper lover behavior from an online community sample. The Journal of Sex Research. https://doi.org/10.1080/00224499.2017.1373728.

Publisher's Note Springer Nature remains neutral with regard to jurisdictional claims in published maps and institutional affiliations. 